\title{
A novel modified nasal PAP mask assembly maintained spontaneous ventilation and oxygenation in a morbidly obese patient with severe obstructive sleep apnoea and asthma during ambulatory hysteroscopy and D\&C under spinal anaesthesia
}

\author{
James Tse, PhD, MD, Vrajesh Mehta, MD, Justin Roberts, MD, Sylviana Barsoum, MD
}

Dept. of Anesthesiology, Rutgers Robert Wood Johnson Medical School, New Brunswick, NJ, USA

ePoster Presentation (02AP02-1) at the Euroanaesthesia 2018 , Copenhagen, Denmark, 2 - 4 June 2018

Background: Patients under regional anaesthesia often receive IV sedation and $\mathrm{O}_{2}$ via nasal cannula. Over-sedation and/or airway obstruction may cause desaturation.

A novel nasal PAP mask assembly was shown to maintain spontaneous ventilation and oxygenation in obese patients under sedation (Fig. 1). ${ }^{1-5}$

We report its use in a morbidly obese OSA patient under spinal anaesthesia.

Case Report: A 56 y/o female, $163 \mathrm{~cm}, 124 \mathrm{~kg}$, BMI 47, with HTN, NIDDM, OSA on CPAP, asthma presented for hysteroscopy and D\&C. She was anxious due to two previous anaesthesia complications.

She reported "a near respiratory arrest" under propofol sedation for colonoscopy and required assisted mask ventilation which resulted in aspiration pneumonitis.

She also developed respiratory failure and required re-intubation after knee arthroscopy. She had severe orthopnoea and a Mallampati Class IV airway.

To fit an adult nose, an infant face mask was modified by squeezing the mask for 2 minutes (Fig.2-3). The patient gave her consent for using the modified nasal mask and taking photographs for educational purposes.

Spinal anesthesia was attempted with a $25 \mathrm{G}$ pencilpoint needle in sitting position. However, she developed vasovagal reaction with bradycardia and lightheadedness.

After her symptoms were resolved, spinal anaesthesia was performed in LLD position with $22 \mathrm{G}$ cutting needle with $1.6 \mathrm{cc}$ of $0.75 \%$ bupivacaine.

A modified infant mask with a fully inflated air-cushion was secured over her nose with elastic head straps and connected to the anaesthesia machine via a breathing circuit.

She was breathing comfortably with $8 \mathrm{~cm} \mathrm{H}_{2} \mathrm{O}$ nasal CPAP by adjusting APL valve with $4 \mathrm{~L} \mathrm{O}_{2} /$ min (Fig. 4).

She maintained spontaneous ventilation and $98-100 \%$ $\mathrm{SpO}_{2}$ throughout hysteroscopy and D\&C in lithotomy position (Fig. 5).

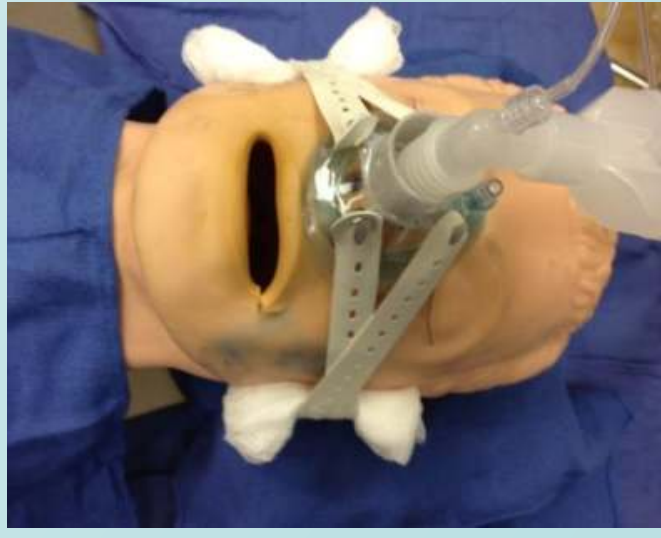

Fig. 1. An infant mask was secured over the nose with head-straps.

Fig. 2. To modify the infant face mask by squeezing the mask for 2 mins.

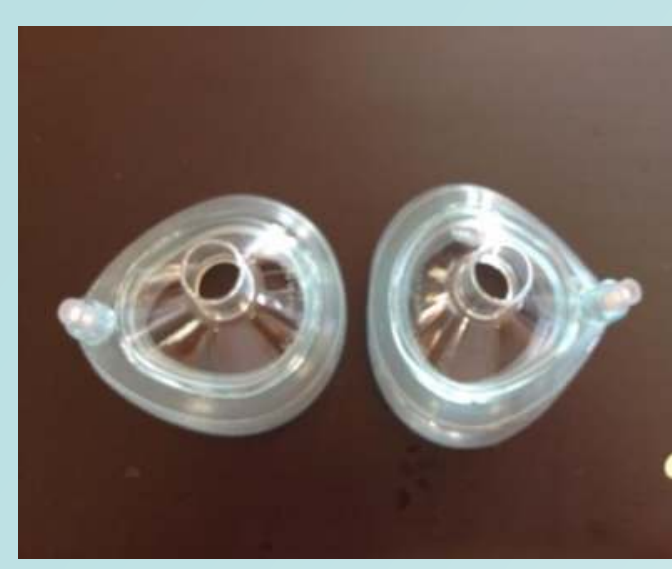

Fig. 3. Infant face mask (left) vs. modified infant face mask (right)

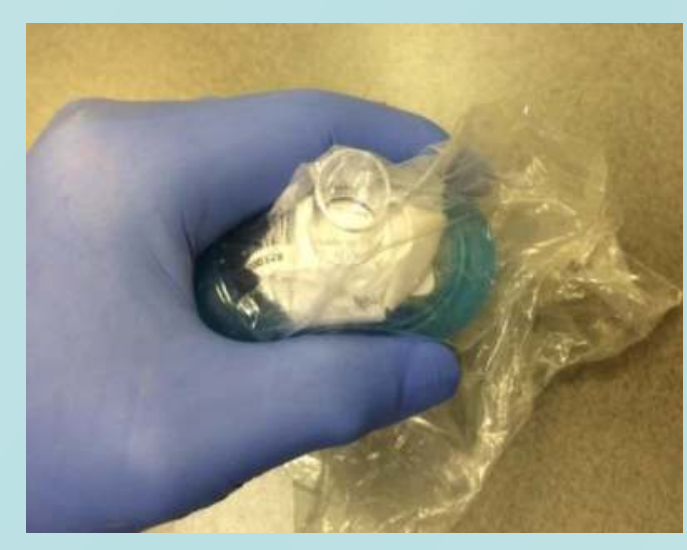

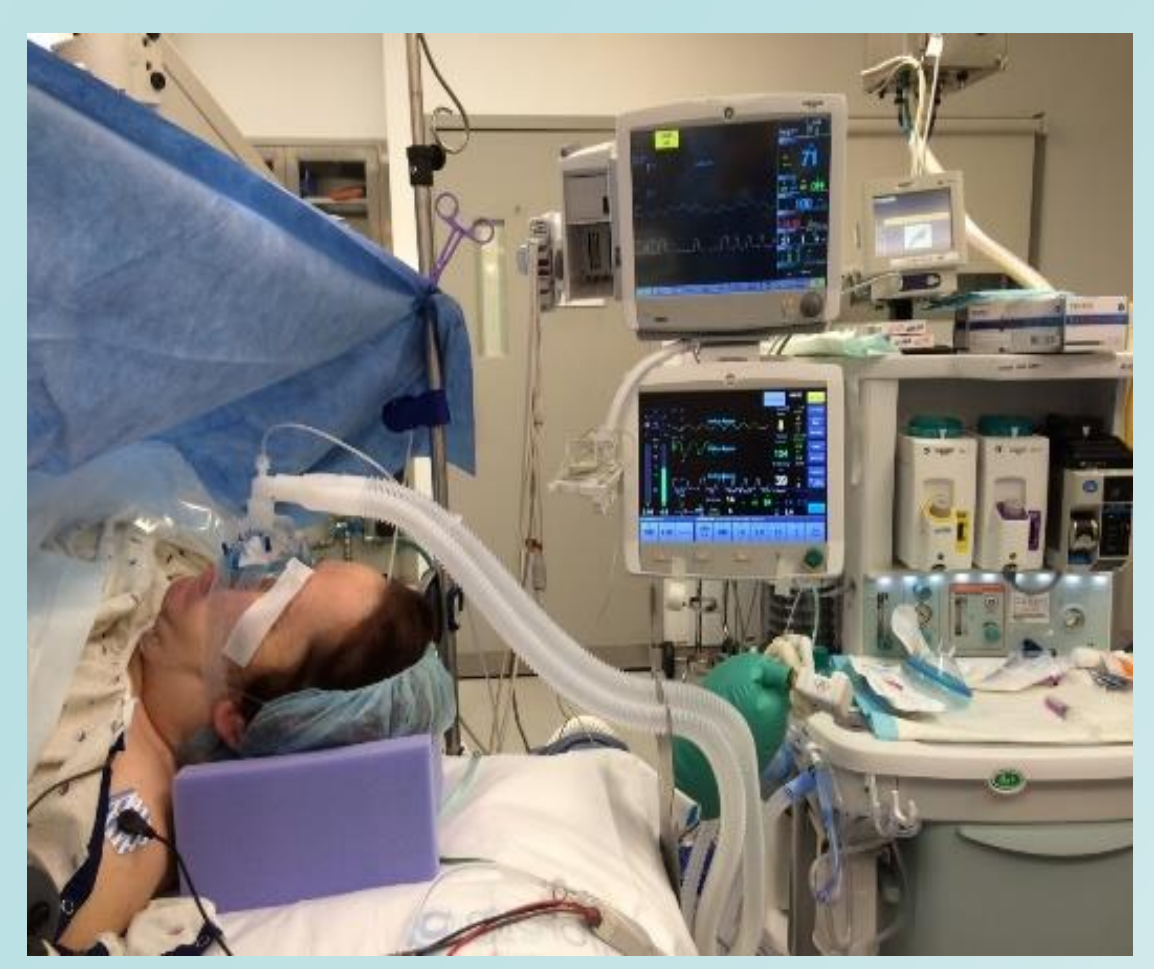

Fig. 4. The patient breathing comfortably with $8 \mathrm{~cm} \mathrm{H} \mathrm{H}_{2} \mathrm{O}$ nasal CPAP throughout.

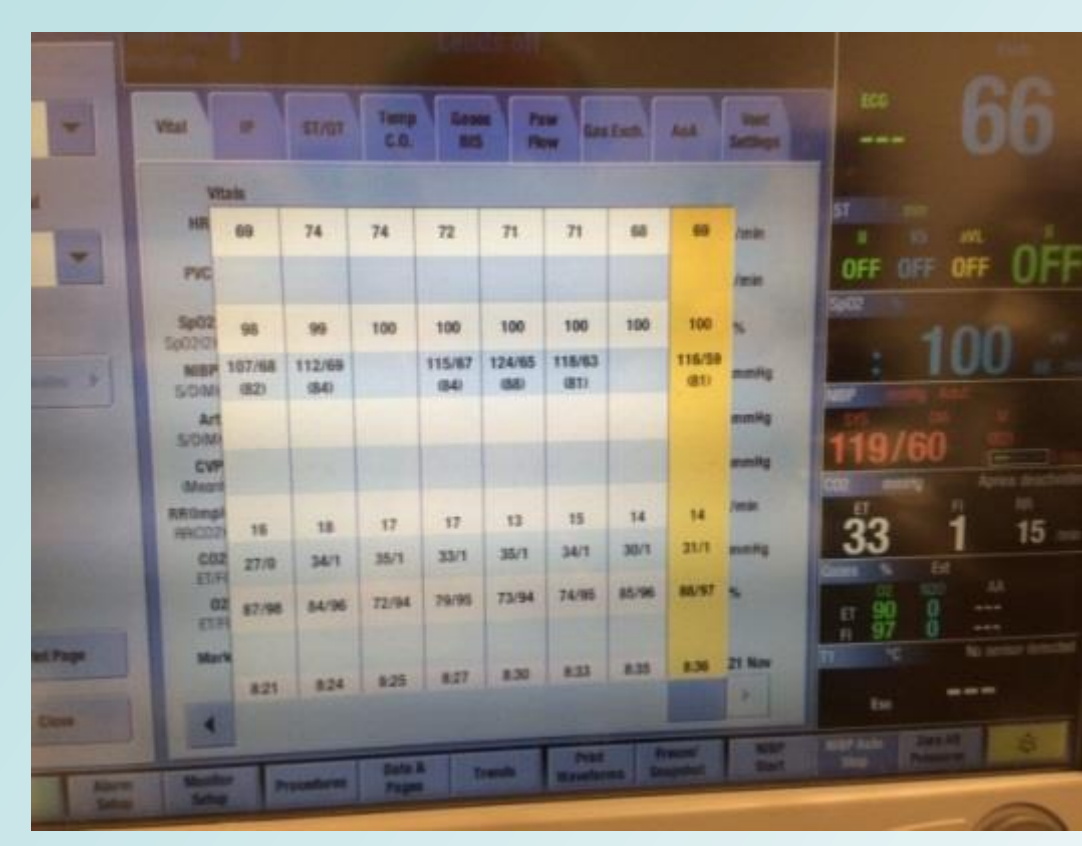

Fig. 5. The patient maintained $98-100 \%$ $\mathrm{SpO}_{2}$ throughout
She was elated that the procedure was completed without any complication.

Discussion:This modified nasal PAP mask assembly maintained spontaneous ventilation and oxygenation in a morbidly obese patient during hysteroscopy/D\&C under spinal anaesthesia.

This avoids the need to intubate the patient to maintain a patent airway and post-extubation complications.

References: 1.www.TSEMask.com;2.SAMBA 28th AM, 2013; 3.SASM 3rd AM, 2013; 4. 67th PGA, 2013; 5.ASAAM, 2015

\section{Learning points:}

!. How to modify a paediatric mask to fit the nose and construct the nasal PAP mask assembly in <2 min.

2. How to adjust APL valve to provide optimal CPAP. 